\title{
In Memoriam Dr Jürgen E. Winter
}

With the death of Dr Jürgen E. Winter on June 30 the aquatic science community lost a valued colleague and a dear friend.

Jürgen Winter was born on October 23, 1937 in Schneidemühl, Germany. In 1969 he received his doctor's degree from the University of Hamburg. In the same year he joined the 'Institut für Meeresforschung' in Bremerhaven as an assistant researcher, moving up the ranks to become director of the Zoology Department of that institute from 1974 to 1977 . In 1977 he 'emigrated' to southern Chile, on the invitation of the Universidad Austral de Chile, Valdivia. Here he found great attraction in the new environment and began an energetic academic activity in the field of aquaculture.

From 1982 to 1986 Jürgen was president of the 'Comité de las Ciencias del Mar-Chile', the most important association of marine scientists in Chile. $\mathrm{He}$ established the 'Centro de Investigaciones Marinas' in 1981 with two experimental aquacultural stations on Chiloé Island (Quempillén and Yaldad), southern Chile. These two aquaculture stations with wellequipped laboratories received his main interest during the past 10 years, because, as well as being used for academic purpuses such as research and teaching, they enabled the university to develop aquacultural activities in southern Chile. In 1985 he founded the School of Marine Biology at the Universidad Austral de Chile and became its Director, a position he held until his death. In 1989 he also founded the 'Instituto de Biología Marina' of the Faculty of Science, which he headed until 1992.

Jürgen Winter was, at least during the years I knew him (over 15), among the most humble human beings of my acquaintance. His friendly manner and energetic speech were combined with enthusiasm, keen wit, and outstanding intellectual ability. Jürgen always spoke kindly of his former students and was closely interested in their careers.

While he was not much dedicated to classroom teaching, outside the lecture room students had the fortune to find in him (the 'doc' as they referred to him) an inexhaustible source of information. Jürgen was knowledgeable in virtually every aspect of marine biology, and in a wide variety of other subject areas. In his many conversations with the students who often surrounded him, he always had some tidbit of information that was new to them. Working late at night in the university, his door was always open for anyone who asked for advice, literature or some specialized instrument. He always had time for those who needed him.

In addition to his administrative responsibilities, Jürgen remained active in the academic field. He worked on the editorial boards of

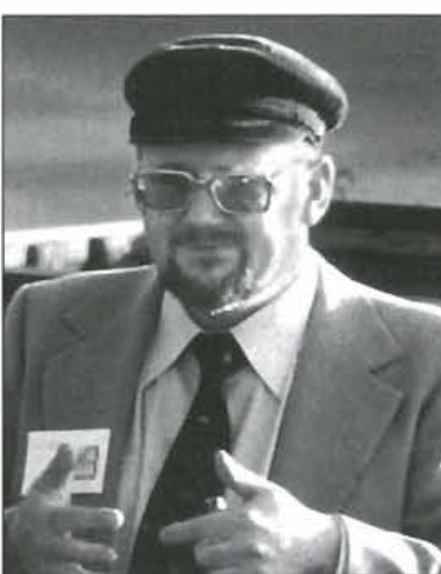

Dr Jürgen Winter, 1937-1994 Marine Ecology Progress Series, Marine Biology, Vie Marine, Revista Chilena de Historia Natural, Estudios Oceanológicos and Investigación Pesquera. His gentle self-deprecating charm enabled him to move as easily among fishermen and fishing industry representatives, the general public, students, and goverment officials, as among his colleagues. His involvement with aquaculture activities in southern Chile was multifaceted, working very closely with artisanal fishermen and in educational programs for rural teachers on aquaculture. Several projects concerning social and basic research were in process until last June.

His life's work and accomplishments point out a significant lesson: dedicated individuals have to struggle to get their scientific plans and intellectual messages through to politicians, managers, and the lay public, and to overcome the inertia of the system. Only thus can ideas persist, to the benefit of future researchers and society. If we can make just a small fraction of the contribution to science and society that Jürgen made in his time, we will have done well. Those of us who were Jürgen's students can only hope that some of the knowledge, dedication, high ethical standards, and love of life that he transmitted has been kept alive in us and passed on to our students.

I'll miss you, Jürgen.

Jorge E. Toro

Instituto de Biología Marina, Universidad Austral de Chile, Casilla 567, Valdivia, Chile 